\title{
Moral Responsibility Reconsidered: Integrating Chance, Choice and Constraint
}

\author{
Abraham Rudnick \\ Department of Psychiatry and School of Occupational Therapy, Dalhousie University, Halifax, Nova Scotia, Canada
}

Email address:

harudnick@hotmail.com

To cite this article:

Abraham Rudnick. Moral Responsibility Reconsidered: Integrating Chance, Choice and Constraint. International Journal of Philosophy. Vol. 7, No. 2, 2019, pp. 48-54. doi: 10.11648/j.ijp.20190702.11

Received: February 4, 2019; Accepted: March 15, 2019; Published: April 9, 2019

\begin{abstract}
Clarity is needed regarding moral responsibility, for theoretical and practical purposes, such as philosophical coherence and social regulation. In this article, I examine the notion of (individual) moral responsibility. I first dispense with a preliminary concern, that the notion of moral responsibility can be used in at least two distinct ways, which I argue are necessarily related and hence can be jointly addressed in this article. I then elaborate on what I consider to be the three key tenets of the proposed theoretical approach: chance, choice and constraint (which can hence be termed the 3Cs theory of responsibility); specifically, I consider chance as indeterminate (although calculable), whereas choice and constraint are determined by chance and by each other. I then integrate these tenets to form a rudimentary yet useful theory of (individual) moral responsibility, particularly referring to the iterative process of chance, choice and constraint. And then I apply this theory to three sufficiently dissimilar types of situations of ascending complexity: the responsibility of a democratically elected politician regarding his or her public communication, the responsibility of a person with psychosis regarding his or her psychosis-related behavior, and the responsibility of a parent regarding his or her dependent child's upbringing. Finally, I summarize and attend to special and general implications of my conclusions, such as the importance of considering expected rather than actual - impact of chance, choice and constraint, during moral deliberation for assignment of (individual) moral responsibility.
\end{abstract}

Keywords: Chance, Choice, Constraint, Individual, Moral, Responsibility

\section{Introduction}

The discussion of moral responsibility for (in)action is longstanding in philosophy and theology. For example, questions have been raised about who if anyone is morally responsible for starting, continuing and ending wars. An instance of that is the fact that J. F. Kennedy is not widely considered responsible for starting or at least continuing the early stages of America's war in Vietnam, although historical evidence clearly suggests his responsibility for that; in addition to scholarly work, a recent television documentary series provides evidence on J. F. Kennedy's (lack of bold) leadership during the immediate antecedents of the American war in Vietnam; the series is accompanied by a book by Ward and Burns [1]. Another example is the question who if anyone is morally responsible for the advent, growth and sustenance of consumerism in the last century or so, e.g., executives in the advertising private sector are often considered directly responsible for growing and even more so sustaining consumerism, although historical evidence clearly suggests that many other factors contribute to this; even in the United States of America (USA), where rampant consumerism as we currently know it was first developed and is perhaps still most prominent, various interacting economic, political, cultural and other social factors have led by design and otherwise to consumerism, as described and analyzed in a book by Cross [2]. And yet another example is the question who if anyone is morally responsible for the pitiful condition of public primary and secondary education in some countries such as the USA, e.g., Facebook's founder Mark Zuckerberg is widely considered to have taken moral responsibility for this due to his donation of 100,000,000 US Dollars into New Jersey's public school system in 2010 (both research and journalism have recently suggested that the donation of 
$\$ 100,000,000$ by Mark Zuckerberg with another $\$ 100,000,000$ matched by other donors to improve the public schools system in New Jersey have not made much if any significant difference, perhaps because of being mishandled, e.g., as reported by Garfield [3]; admittedly, this was philanthropic action on the donors' part and hence supererogatory which may not count towards moral responsibility. There are many other such questions.

For clarity, it is helpful to note that moral - rather than other, such as legal and social - responsibility addresses questions of who should - rather than who must and who commonly seems to, respectively - have responsibility. For simplicity, I will refer to having moral responsibility, although it is not clear that having moral responsibility is the only or best way to refer to moral responsibility, e.g., colloquially one may take moral responsibility and more formally one may confer or incur moral responsibility. Be that as it may, an important problem to address is that there is no sufficient agreement on what is moral responsibility and hence there is no sufficient clarity on how to apply it. Note that moral responsibility has been studied theoretically (philosophically and otherwise) as well as empirically (regarding policy and practice) fairly extensively, yet there is still no consensus nor even wide agreement on it, as demonstrated in recent texts about it such as in a book by Talbert [4] and in even more recent conferences such as summarized in a journal issue by Ceva and Radoilska [5]. Such agreement and clarity are needed for theoretical and practical purposes, such as philosophical ethics deliberation and social regulation implementation, respectively.

In this article, I examine the general notion (rather than special concepts) of moral responsibility, using standard philosophical tools, particularly arguments and examples, with a somewhat eclectic but theoretically coherent use of published writing, referring to common morality more than to specific or specialized theories of morality. Common morality is a notion used particularly in bioethics, according to which moral principles, norms or standards are commonly shared and implicitly used by humans who are morally serious (presumably these are people who want to do the morally right - or best - thing). This approach provides a set point of reference from which to address moral arguments, as is often done in bioethics, e.g., as elaborated in a book by Gert [6]. The normativity (rather than the occurrence) of common morality, i.e., its "ought" rather than its "is", has been recently argued for, e.g., in an article by Bautz [7]. In my article I will assume some basic common morality as normative, e.g., the importance of upholding selfdetermination, optimally balancing benefit and harm, and justly considering others (recognizing that these principles sometimes conflict with each other in particular contexts and therefore ways of resolving such conflicts are needed in addition to the principles); in bioethics, this approach has been specified as principlism, e.g., as addressed in an article by Azambuja and Garrafa [8].

Note that I don't address collective responsibility, as moral responsibility is arguably ultimately a personal issue, whatever the circumstances are, and as even if collective moral responsibility can be convincingly argued to be irreducible to individual moral responsibility, there would then be further issues to address - such as the relation between individual responsibility and collective responsibility - which are out of scope for this article for lack of space if nothing else. Arguably, collective moral responsibility may be reduced to individual moral responsibility by various means, such as aggregating additively and synergistically - the (in) actions of all individuals involved, e.g., as illustrated in a book by Cowley [9]. Although practical aspects of such aggregating may be challenging, e.g., logistically difficult and computationally complicated, in principle this is possible assuming that moral responsibility is not collectively irreducible.

Also note that I address moral responsibility as impacting on others, as such responsibility is arguably not applicable to oneself, although related notions may apply to oneself, such as autonomy or self-determination (which, as they are not directly related to this article's topic, and for lack of space, I do not address). This argument may apply to the case of suicide as well, with the caveat that suicide may be considered to be morally irresponsible to oneself if one is religious and as part of that one believes in the soul and its damnation due to suicide; assuming that the soul is part of oneself when still living (which is presumably not controversial), and that the soul is necessarily a part of oneself that is responsible for one's decisions such as to commit suicide (which is also presumably not controversial), then if one is religious and as part of that one believes in the soul and its damnation due to suicide, one is morally responsible for one's suicide (and hence one's soul is damned if one commits suicide). As detailed theological discussion is out of scope for my article, I will not address this case of moral responsibility to oneself, for which see established writings such as the book by Niebuhr [10]. Due to lack of space and no direct relevance for this article, I will also not address the question of other moral responsibility to oneself, other than to state that I believe that if there is responsibility to oneself, it is not moral but rather legal or perhaps psychological, such as being responsible to follow through on promises to self (which are often not followed through yet that is not typically considered morally problematic, e.g., when people commonly do not follow through on new year promises to themselves). For a more general discussion of why there is no moral responsibility to oneself, see a recently published article by Gronholz [11].

Following this introduction, in section 2, I dispense of a preliminary concern distinguishing moral responsibility for particular (in) actions versus moral responsibility as a set of duties or obligations. In section 3, I elaborate on what I consider to be the three key tenets of this theoretical approach: chance, choice and constraint (which can hence be termed the 3Cs theory of responsibility), and I then integrate these tenets to form a rudimentary yet 
useful theory of (individual) moral responsibility. In section 4 I apply this theory to three dissimilar situations of ascending complexity: the responsibility of a democratically elected politician regarding his or her public communication, the responsibility of a person with psychosis regarding his or her psychosis-related behavior, and the responsibility of a parent regarding his or her dependent child's upbringing. In section 5, I summarize and then attend to special and general implications of my conclusions.

\section{Moral Responsibility for Particular (in) Actions Versus as a Set of Duties or Obligations}

When philosophers discuss moral responsibility, they typically address a relation between an agent and his or her (in)action such that it can make sense to merit or dismerit him or her for those (in)actions. Thus, we can state that one is morally responsible for a particular (in) action. On the other hand, in lay use, one hears that one has moral responsibilities, where these responsibilities are something like a set of duties or obligations. A preliminary concern may be that this paper could be viewed as seeming to shift between these two usages, which may limit its ability to interact fruitfully with relevant debates. I will now address this concern by arguing that these two usages are not distinct but rather necessarily related to each other so that addressing one or the other is addressing the same fundamental issue of moral responsibility. Moral responsibility is presumably assigned to (in) action that has already occurred. Duties or obligations refer to normative expectations for (in)action, so they seem to address future (in)action. Yet norms that govern or guide moral responsibility ascription would or should arguably not change in relation to whether they are ascribed before or after the fact of (in) action. Hence, moral responsibility for particular (in) actions would or should be compatible with relevant duties or obligations. In addition, moral responsibility refers to particular (in) actions, whereas duties or obligations refer to types of (in) action, such as in relation to types of situations. To use a simple although not necessarily simplistic account of the notion of types, types are an aggregate of pertinently similar tokens; a type of (in) action is an aggregate of (in) actions all of which are guided by the same norms. Hence, duties or obligations can be viewed as derivatives of norms that guide moral responsibility ascription for particular (in) actions. Thus, duties or obligations and moral responsibility for (in) action are compatible with each other and may be logically entailed one by the other, and can therefore be addressed jointly in this article. This argument aligns with a common definition of moral responsibility as 'the status of morally deserving praise, blame, reward or punishment for an act or omission performed or neglected in accordance with one's moral obligations' (https://en.wikipedia.org./wiki/Moral_responsibility).

\section{Towards a Theory of (Individual) Moral Responsibility}

\subsection{Chance, Choice and Constraint}

Chance seems self-evident. It may be trivial to state that chance plays a large role in people's lives and arguably in everything else, determinism aside (even a strict determinist may have to concede that everything - our universe or the multiverse if more than one universe exists - may all have started by chance or by decree that itself could be the result of chance; for argumentation in support of the compatibility of determinism and chance, see writings such as by Eagle [12]). By chance I mean an event that is generated randomly rather than by specific causation of whatever type. The characterization of randomness may be done mathematically or otherwise, which does not necessarily influence its effect(s), the latter being of principal interest for this article. It is obvious that chance limits (individual) moral responsibility, as by definition chance is not generated by people (although they can disrupt or otherwise override it such as when cheating in chance games). On the other hand, chance alone does not fully determine actions and inactions, as people's choices determine - at least in part - what events involving them occur (recognizing that events involving people are comprised of intra-personal, inter-personal, extrapersonal and perhaps other aspects, and that some choices may determine only some of these aspects and not others).

Choice is not as self-evident as chance. Choosing involves determining to do something, which entails not doing other things which are not possible to do in conjunction with what is determined to be done. This characterization applies symmetrically to determining to not do something; choosing also involves determining not to do something, which entails not doing other things which are not possible to do in conjunction with what is determined to not be done. Note that choice is more fundamental than decisions, which operationalize it and thus can be changed, without changing the choice related to them, if they do not optimize this choice's operationalizing. Choice is distinct if not unique to persons and other types of self-determining agents, as without it self-determination does not seem possible; a more formal although tentative argument is that choice is necessary and perhaps sufficient for self-determination (it may be the other way around, i.e., that self-determination is necessary and perhaps sufficient for choice; the former argument may refer to a logical relation between choice and selfdetermination whereas the latter argument may refer to a causal relation between self-determination and choice; I do not examine this relation as it is not required as part of the conceptual work that has to be done in this article and hence it is out of scope for this article). Choice is necessary for (individual) moral responsibility, as I argued above that without choice there is no self-determination, and as it is well established that without self-determination there is no moral (or any other) responsibility. Thus, choice is necessary but perhaps not sufficient for (individual) moral responsibility, 
and chance randomly limits (individual) moral responsibility. Constraints are similar to chance in limiting (individual) moral responsibility, yet unlike chance they are not (only) randomly determined.

Constraint may be the least self-evident, compared to chance and choice. It is imposed by the person's physical and social environment, which can be determined only in part by chance and by choice. Constraint is construed here as related to physical and social aspects of one's environment, where physical aspects include all matter and energy related factors (including biological and other factors), whereas social aspects include all information related factors (including cultural and other factors), assuming that information is distinct from matter and energy, as originally argued a few decades ago by pioneers of information theory such as in the seminal book by Wiener [13], and more recently addressed in much detail such as in whole issues of academic journals, e.g., as reviewed by Crnkovic [14]. Such a construal is broad enough to include all relevant aspects of one's environment. If there are other aspects of environments, they are arguably not relevant in this context. Physical constraints are things such as laws of nature, topography and related climate, and more. Social constraints are things such as state laws and regulations, social norms, and more. Constraints limit choice but can also help transform it by providing an opportunity to reconsider options and, following that, change choice. Thus, constraint both limits and can enhance choice. As such, constraint is related to (individual) moral responsibility similarly to both chance and choice; it both limits and may enhance (individual) moral responsibility, the latter through its possible transformation of choice.

\subsection{A Rudimentary Theory of (Individual) Moral Responsibility}

Before I integrate chance, choice and constraint to develop a rudimentary theory of (individual) moral responsibility, I now commit to a definition of responsibility. This has not been done in this article until now as starting with commitments to definitions is not always helpful, not only because definitions are true by convention (which may and does differ across time and space, although it can provide a starting point for discussion), but also because they may unnecessarily restrict the discussion too early by limiting it to derivatives of a selected definition. In any case, a relevant definition of responsibility is to have a duty or an obligation to do or not do something. Accordingly, (individual) moral responsibility refers to what should be the duty or obligation of a person or another type of self-determining agent to do or not do something.

Arguably, the three tenets of choice, chance and constraint are each necessary and jointly sufficient for a theory of (individual) moral responsibility. As it is out of scope for this article to argue for such a sufficiency, I will address choice, chance and constraint as jointly necessary for a theory of (individual) moral responsibility. So what is the conceptual relation between chance, choice and constraint, and how does that relate to (individual) moral responsibility?
Chance is not dependent on choice and on constraint. Choice is partly dependent on chance and on constraint (as choice is limited by chance and by aspects of the environment). Constraint is partly dependent on chance and on choice (as choice may transform aspects of the environment). Hence, chance and choice may transform constraint, and chance and constraint may transform choice. Thus, the interaction between chance, choice and constraint is iterative (other than chance being independent), hence it is dynamic, involving the possibility of transforming choice and constraint in the process. Therefore, a rudimentary theory of (individual) moral responsibility based on the three tenets chance, choice and constraint - can address the temporal dimension, which allows application to real life - dynamic situations.

This rudimentary theory of (individual) moral responsibility, i.e., the $3 \mathrm{Cs}$ theory of responsibility, includes the three tenets - chance, choice and constraint - and their transformation of each other over time (other than chance being un-transformable). According to this theory, persons and other types of self-determining agents should morally choose in relation to their changing context, i.e., based not only on their moral principles or values but also based on limitations on their choice imposed by chance and constraint as well as based on expected transformations of constraint and of consequent choice resulting from their initial choice. Note that this may be an example of the possible complementarity of an intent based moral theory approach (of which deontology is the best known special case) and an expected impact based moral theory approach (of which consequentialism or utilitarianism is the best known special case). Such choice in relation to changing context is complex as it may iteratively impact on itself, hence persons and other self-determining agents may have to use special means skills, tools and more - to predict or otherwise comprehend the impact of their choice. Complexity theory may help with such special means, although examining the latter is outside the scope of this article which is theoretical rather than practical. How does this rudimentary theory of (individual) moral responsibility test when applied to three sufficiently dissimilar types of situations of ascending complexity?

\section{Application of the 3Cs Theory of Responsibility}

\subsection{Public Communication by a Democratically Elected Politician}

The moral responsibility of a democratically elected politician regarding his or her public communication seems simple, at least according to common morality, i.e., to tell the known truth so long as it does not compromise public safety; of course, the devil is in the details of what is considered public safety, but that can be discussed and decided in advance in camera with an appropriate and presumably secure forum such as with the cabinet in the case of ministers and prime ministers. Such truth telling is not only valuable in 
a democracy as an end in itself but can also serve as a helpful means to allow public input for government's course correction as needed. Using the 3Cs theory of responsibility, this democratic approach can be formulated as the politician making a choice to tell as much of the truth as possible within the constraint of public safety that can be influenced by chance such as a natural disaster that may cause mass casualties in which case truth telling may be more limited, at least initially, to try to minimize public panic and related disorder (although social media may disrupt such truth telling limitation attempts of authorities). The 3 Cs theory would not support a democratically elected politician telling outright lies to the public as that would be considered an immoral choice whatever the circumstances are. In this situation, the $3 \mathrm{Cs}$ theory of responsibility reaches similar conclusions to those of common morality and likely other moral theories such as the contractarian approach that arguably morally grounds liberal democracy. Hence, the 3Cs theory of responsibility has no distinct advantage or disadvantage in this application.

\subsection{Psychosis Related Behavior of a Person with Psychosis}

The moral responsibility of a person with psychosis regarding his or her psychosis related behavior is a more complex situation than the previous one. At least according to common morality, a person whose reality testing is impaired (which is a common definition of psychosis) and who acts on his or her psychosis such as delusional beliefs or hallucinatory perception is exempt from moral responsibility for these behaviors as he or she could not know better or even differently (arguably, psychosis is similar if not identical to reinforced dogmatism which does not typically exempt from moral responsibility; the most well-known example of the similarity of reinforced dogmatism and psychosis is the notion of the "mad scientist"; for philosophical and other discussion of this example and the similarity and distinction of reinforced dogmatism and psychosis, see a book by Fried and Agassi [15] and its critical yet sympathetic follow up article by Rudnick [16].

This exemption approach is similar to that of many legal approaches to the insanity defense in relation to criminal responsibility. According to the 3Cs theory of responsibility, this common morality approach is simplistic as it focuses on constraint (and perhaps chance, considering that psychosis may be a chance event for many people) to the exclusion of choice. A biblical example published by Rudnick [17] may help illustrate why choice can be a key consideration in relation to (individual) moral responsibility of a person acting on his psychosis (my apologies to historians for the possible anachronism and to monotheists for psychopathologizing and therefore perhaps secularizing this example; it is done here for illustration's sake rather than with sacrilegious intent). Abraham's willingness to sacrifice his son Isaac based on hearing God asking him to do that can be considered as acting to harm his child as a show of faith in God based on experiencing auditory hallucinations. Abraham had a choice to make - act on God's imperative as he attempted to do, or disobey it and then perhaps lose God's trust in him as the founder of monotheism. God's ask is not portrayed as a constraint in the bible, as Abraham is free to choose whether to act on it or not. Thus, according to the 3Cs theory of responsibility, Abraham was morally responsible for his choice to sacrifice his son even though he acted on what may be viewed as auditory hallucinations. To my mind, Abraham was also culpable for his choice, at least if his son's innocence (at that stage of his life) is considered. Furthermore, if Abraham had chosen not to try to sacrifice his son, the morality of Judaism - and perhaps of all of monotheism - may have developed differently, perhaps involving more compassion to others (it may be argued that Jesus countered Judaism's lack of compassion with his new monotheism, which was short lived as a compassionate religion).

The 3Cs theory of responsibility thus helps clarify that people with psychosis may be responsible for their psychosis-related behavior, depending on the particular circumstances or constraints, e.g., if a person with psychosis believes that another person is possessed and planning to kill him or her immediately, he or she may not be morally responsible for killing, hurting or at least neutralizing that other person as a form of self-defense, but if he or she hears a voice - even that of God - telling him or her to kill or hurt that other person without believing that the other person poses an immediate risk to himself or herself, he or she may be morally responsible for killing or hurting the other person (even if he or she believes that he or she will be damned to hell if he or she does not kill or hurt the other person). In this situation, the $3 \mathrm{Cs}$ theory of responsibility reaches different more constraint-dependent - conclusions than those of common morality and other moral theories such as those grounding insanity defenses, and hence the $3 \mathrm{Cs}$ theory of responsibility has the distinct advantage in this moderately complex application of being more nuanced compared to other moral responsibility theories.

\subsection{Upbringing of a Dependent Child by a Parent}

The moral responsibility of a parent regarding his or her dependent child's upbringing is a particularly complex situation as it can last for many years (including into the child's adulthood, e.g., if the child is developmentally disabled) and it can change considerably depending on the child's age and more importantly on the child's degree of maturity. Many if not all approaches to a parent's moral responsibility to his or her dependent child require that the parent provide the child with an environment that is at the minimum safe and health-conducive. According to the $3 \mathrm{Cs}$ theory of responsibility, constraint may limit that such as in very poor families who are powerless to change their socioeconomic situations (as often occurs in some developing countries), so that in some family situations the $3 \mathrm{Cs}$ theory of responsibility may be less demanding than other moral responsibility theories. A fairly neglected question regarding parental upbringing is what is the parent's moral responsibility to help his or her dependent 
child acquire skills to thrive as well as to survive later in life, e.g., technical skills, emotional skills, intellectual skills, social skills and more. Of these, intellectual skills in particular such as mathematics are often delegated by parents to schools, whereas emotional skills in particular such as self-soothing are often neglected or disrupted by indifferent or intrusive parents, respectively. According to the $3 \mathrm{Cs}$ theory of responsibility, a parent's moral responsibility to his or her dependent child may extend to helping the child acquire as many of these skills as possible, if chance and constraint do not limit that (such as by genetic impairment and poverty, respectively), as parental choice is not limited to only consider the child's surviving but can extend to the child's thriving. An important nuance is that such parental moral responsibility for the dependent child's acquiring skills to thrive as well as to survive may differ across the dependent child's development, although whether there is a progressively decreasing or progressively increasing or a more complex set of moral requirements requires further clarification that is partly dependent on empirical information about child development and is out of scope for this article.

A pertinent point in relation to the $3 \mathrm{Cs}$ theory of responsibility is that choice may change constraint, e.g., a parent can and arguably should choose to self-sacrifice his or her well-being such as working more than one job in order to reduce the family's poverty and thus provide more opportunities - including in relation to acquiring skills to thrive as well as to survive - for his or her dependent child. Perhaps even more importantly, parental moral responsibility may include role modeling and other means of parental guidance for his or her dependent child, in order to help the child as much as possible to acquire skills to thrive as well as to survive. If so, recommended training for parents may be required, as such guidance does not seem easy or simple for many parents. Perhaps parenting schooling or other training should be required, according to this approach, although addressing pros and cons of this suggestion is out of scope for this article. In any case, in this situation, the $3 \mathrm{Cs}$ theory of responsibility reaches different - more choice-focused - conclusions than those of common morality and other moral theories such as those presumably grounding current family legislation (that does not require parental training), and hence the $3 \mathrm{Cs}$ theory of responsibility has the distinct advantage in this considerably complex application of addressing an issue that is fairly neglected by other moral responsibility theories.

\section{Conclusion}

\subsection{Summary}

Moral responsibility of persons and other self-determining agents is an important matter. The 3Cs theory of responsibility, proposed and applied in this article, provides a rudimentary theory of (individual) moral responsibility that involves the key tenets of chance, choice and constraint which are at least partly independent of each other yet interact to transform each other (excluding chance which is untransformable). Applying this theory results in similar conclusions as those of common morality and other moral theories in relation to a simple situation and has distinct advantages compared to common morality and other moral theories in relation to some complex situations.

\subsection{Implications}

This article's conclusions have specific implications, related to the three examples that the $3 \mathrm{Cs}$ theory of responsibility is applied to in this article. First, as democratically elected politicians should choose to tell the truth to the public within constraints of public safety that should be discussed and decided on in advance in an appropriate presumably secure forum, processes should be established and maintained to ensure that such discussions occur when needed, and to report and address untruth telling to the public by democratically elected politicians (within such constraints). Second, as people with psychosis may be morally responsible for their psychosis related behavior, depending on choice as well as constraint in specific circumstances, more nuanced ways of assessing this contextdependence and particularly the role of choice in such behavior should be developed, studied, refined and established in practice and in policy. Third, as parents are morally responsible for their dependent children's upbringing, including helping them acquire thriving skills as well as surviving skills for later life, parenting training such as schooling may be required, for which regulation, resourcing and more may have to be addressed.

The elaboration and application of the $3 \mathrm{Cs}$ theory of responsibility has more general implications. First, it is important to address choice as well as constraint (and chance) in relation to (individual) moral responsibility for (in)action. Second, it is important to recognize these tenets' interactions with each other and their impact on both choice and constraint in relation to (individual) moral responsibility for (in)action. Third, it is important to consider expected - rather than actual - impact of chance, choice and constraint, during moral deliberation, for assignment of (individual) moral responsibility. Last, more philosophical inquiry is needed, as well as theoretical elaboration and empirical research, to further develop and examine the $3 \mathrm{Cs}$ theory of responsibility proposed and applied in this article.

\section{Acknowledgements}

This article is inspired by Karl Popper's philosophy and its development into critical rationalism, which convincingly integrates arguments about morality and knowledge.

\section{Conflict of Interest}

The author declares no conflict of interest. 


\section{References}

[1] Ward G, Burns K (2017) The Vietnam war: an intimate history. Knopf, New York.

[2] Cross G (2002) An all-consuming century: why commercialism won in modern America. Columbia University Press, New York.

[3] Garfield L (2018) Mark Zuckerberg once made a \$100 million investment in a major US city to help fix its schools - now the mayor says the effort 'parachuted' in and failed. businessinsider.com, May 12.

[4] Talbert M (2016) Moral responsibility: an introduction. Polity, Cambridge.

[5] Ceva E, Radoilska L (2018) Dimensions of responsibility. Ethical Theory and Moral Practice 21:771-773.

[6] Gert B (2006) Common morality: deciding what to do. Oxford University Press, Oxford.

[7] Bautz B (2016) What is the common morality, really? Kennedy Institute of Ethics Journal 26: 29-45.

[8] Azambuja LEOd, Garrafa V (2015) The common morality theory in the work of Beauchamp and Childress. Revista Bioetica 23:632-641.
[9] Cowley C (2014) Moral responsibility. Routledge, London.

[10] Niebuhr HR (1963) The responsible self: an essay in Christian moral philosophy. Harper \& Row, New York.

[11] Gronholz S (2018) Moral reasons as other-regarding reasons. Ethical Perspectives 25:285-319.

[12] Eagle A (2011) Deterministic chance. Noûs 45:269-299.

[13] Wiener N (1948) Cybernetics: or control and communication in the animal and machine. MIT Press, Cambridge.

[14] Crnkovic GD (2012) Information and energy/matter. Information 3:751-755.

[15] Fried Y, Agassi J (1976). Paranoia: a study in diagnosis. Reidel, Boston.

[16] Rudnick A (2003). Paranoia and reinforced dogmatism: beyond critical rationality. Philosophy of the Social Sciences $33: 339-350$.

[17] Rudnick A (2015). Choice and criminal responsibility of mentally ill offenders: moral reasoning as a likely mediator related to primary secondary and tertiary prevention. Journal of Psychiatry Reform December 15:1-2. 